\title{
Major Latex Protein MdMLP423 Negatively Regulates Defense against Fungal Infections in Apple
}

\author{
Shanshan He ${ }^{1,2,+}$, Gaopeng Yuan ${ }^{1,2,+}$, Shuxun Bian ${ }^{1,2}$, Xiaolei Han ${ }^{1,2}$, Kai Liu ${ }^{1,2}$, \\ Peihua Cong ${ }^{1,2}$ and Caixia Zhang ${ }^{1,2, *}$ \\ 1 Research Institute of Pomology, Chinese Academy of Agricultural Sciences, Xingcheng 125100, China; \\ hess920309@163.com (S.H.); yuangp329@163.com (G.Y.); bb18236767941@163.com (S.B.); \\ hanxiaolei@caas.cn (X.H.); 15615781850@163.com (K.L.); congph@163.com (P.C.) \\ 2 Key Laboratory of Biology and Genetic Improvement of Horticultural Crops, Xingcheng 125100, China \\ * Correspondence: zhangcaixia@caas.cn \\ + These authors contributed equally to this work.
}

Received: 3 January 2020; Accepted: 9 March 2020; Published: 10 March 2020

Abstract: Major latex proteins (MLPs) play critical roles in plants defense and stress responses. However, the roles of MLPs from apple (Malus $\times$ domestica) have not been clearly identified. In this study, we focused on the biological role of $M d M L P 423$, which had been previously characterized as a potential pathogenesis-related gene. Phylogenetic analysis and conserved domain analysis indicated that MdMLP423 is a protein with a 'Gly-rich loop' (GXGGXG) domain belonging to the Bet $\mathrm{v} \_1$ subfamily. Gene expression profiles showed that $M d M L P 423$ is mainly expressed in flowers. In addition, the expression of MdMLP423 was significantly inhibited by Botryosphaeria berengeriana $\mathrm{f}$. $\mathrm{sp}$. piricola (BB) and Alternaria alternata apple pathotype (AAAP) infections. Apple calli overexpressing $M d M L P 423$ had lower expression of resistance-related genes, and were more sensitive to infection with $\mathrm{BB}$ and AAAP compared with non-transgenic calli. RNA-seq analysis of MdMLP423-overexpressing calli and non-transgenic calli indicated that MdMLP423 regulated the expression of a number of differentially expressed genes (DEGs) and transcription factors, including genes involved in phytohormone signaling pathways, cell wall reinforcement, and genes encoding the defense-related proteins, AP2-EREBP, WRKY, MYB, NAC, Zinc finger protein, and ABI3. Taken together, our results demonstrate that MdMLP423 negatively regulates apple resistance to BB and AAAP infections by inhibiting the expression of defense- and stress-related genes and transcription factors.

Keywords: major latex proteins; fungal infections; apple (Malus $\times$ domestica); defense and stress responses

\section{Introduction}

Major latex protein (MLP) is a plant-specific protein that was first identified in opium poppy latex and is widely found in other plants [1,2]. The proteins encoded by genes that are homologous to $M L P$ are known as MLP-like proteins, and had been identified and isolated from cucumber [3], peach [4], ginseng [5], Arabidopsis thaliana [6], melon [7], soybean [8], and grape [9]. The numbers of MLP-like proteins vary between species, for example, $A$. thaliana has 24 MLP-like proteins but grape only has 14 [9].

The MLP protein contains a Bet $\mathrm{v}_{-} 1$ structure and the MLP-like proteins make up the second largest family in the Bet $\mathrm{v}_{-} 1$ protein superfamily [10]. The members of this superfamily respond to biotic and abiotic stresses and play important roles in plant growth and development, including disease resistance, stress tolerance, and development [11-13]. Bet v_1 proteins have a 'Gly-rich loop' (GXGGXG) domain and three-dimensional structure similar to the pathogenesis-related protein PR 
10. The Gly-rich loop is a broad class of domains with nuclease activity that are widely present in phosphorylated and nucleic acid-binding proteins $[14,15]$. At present, the biological role of the MLP protein is not clear, but its responses to the expression patterns of biotic and abiotic stresses indicate that it may play important roles in defense or stress responses [16].

When facing on exogenous biological stress, plants rely on innate immune mechanisms. Previous studies have shown that invading pathogens induce the expression of MLP family proteins that help defend the plant primarily using innate immunity and acquired resistance signals [17]. Chen and Dai [18] cloned the cotton GhMLP and found that it was rapidly induced by fungal pathogen Verticillium dahliae. The expression of GhMLP423 increased in cotton plants during infection by Bemisia tabaci. Using RNA interference to decrease GhMLP423 expression in cotton during B. tabaci infections led to lower peroxidase, and higher superoxide dismutase activity, respectively [19]. Additionally, another study reported that the expression of MdMLP423 (gi|658009573) in apples was down-regulated by infection with the A. alternata apple pathotype (AAAP), a fungal pathogen that causes Alternaria blotch disease [20]. Subsequently, Zhang et al. [21] used differential proteomics analysis to study apple varieties with different levels of resistance to the Alternaria blotch disease, and found that the expression of MdMLP423 was down-regulated after infection by AAAP. Similar studies in tobacco revealed that the expression of NbMLP423-the tobacco homolog of MdMLP423-was significantly up-regulated after infection by A. alternata [22] Furthermore, overexpressing of NbMLP423 in tobacco significantly enhanced the plants resistance to A. alternata and promoted the up-regulation of PR10 (NtPR10).

Plant hormones play various roles in all stages of plant growth and development. Studies have shown that salicylic acid (SA), jasmonic acid (JA), abscisic acid (ABA), gibberellin (GA), ethylene (ETH), and other plant hormones play crucial roles in the defense signaling pathway, and interact with other signaling pathways [23-25]. Previous studies have reported that exogenous SA significantly reduced the expression of the MLP151 gene [5], and exogenous SA increased the transcription of MLP genes in grapes [9], which demonstrate that MLP proteins respond to salicylic acid and are important in plant resistance to biotic stress. ABA plays crucial roles in regulating plant development [26]. Expression of AtMLP43 in A. thaliana was down-regulated by exogenous ABA, and transgenic plants overexpressing AtMLP43 had lower germination rates compared with wildtype plants [27]. Ethylene affects many processes of plant growth and development and plays important roles in resisting a series of biotic and abiotic stresses [20,28,29]. By identifying the $P p M L P 1$ gene in peach, Ruperti et al. [4] found that ethylene can down-regulate the expression of $P p M L P 1$.

Although MLP proteins are involved in various stress responses in plants, the molecular mechanism of the MdMLP423 (gi|658009573) response to biotic stress is not clear. In this study, we cloned the MdMLP423 gene and identified its molecular role. We used RNA-sequencing (RNA-seq) to further analyze the transcriptome of transgenic apple tissue overexpressing MdMLP423, which increased our understanding of the changes in the expression of genes that are closely related to MdMLP423 activity, as well as the possible causes for sensitivity to Botryosphaeria berengeriana $\mathrm{f}$. sp. piricola (BB) and AAAP infections. These two pathogens are major fungal diseases in China, usually leading to enormous damage to apple production [30]. Previous studies have shown that the 'Golden Delicious' (GD) apple cultivar is a more susceptible to BB than the 'Huayue' (HY) cultivar [31,32], and it is also more susceptible to AAAP than 'Hanfu' (HF) [33,34]. 'GD', 'HY', and 'HF' are important cultivars in China and this study has important significance for further resistance breeding.

\section{Results}

\subsection{Isolation and Sequence Analysis of the MdMLP423 Gene}

In a previous study we analyzed the iTRAQ-based proteomics profiles of 'Huayue' apple leaves in response to AAAP infection, and we found that MdMLP423 is a potential allergy related protein, that is involved in stress responses in fruit trees [21]. Here, we cloned the MdMLP423 gene from the 'Golden Delicious' apple variety. The coding sequence of MdMLP423 was $462 \mathrm{bp}$ in length, and it 
encoded a putative protein of 153 amino acids with a calculated molecular mass of $16.92 \mathrm{kDa}$ and an isoelectric point of 4.97. SMART analysis showed that MdMLP423 contained a Bet v_1 domain (residues 3-153; Figure 1B).
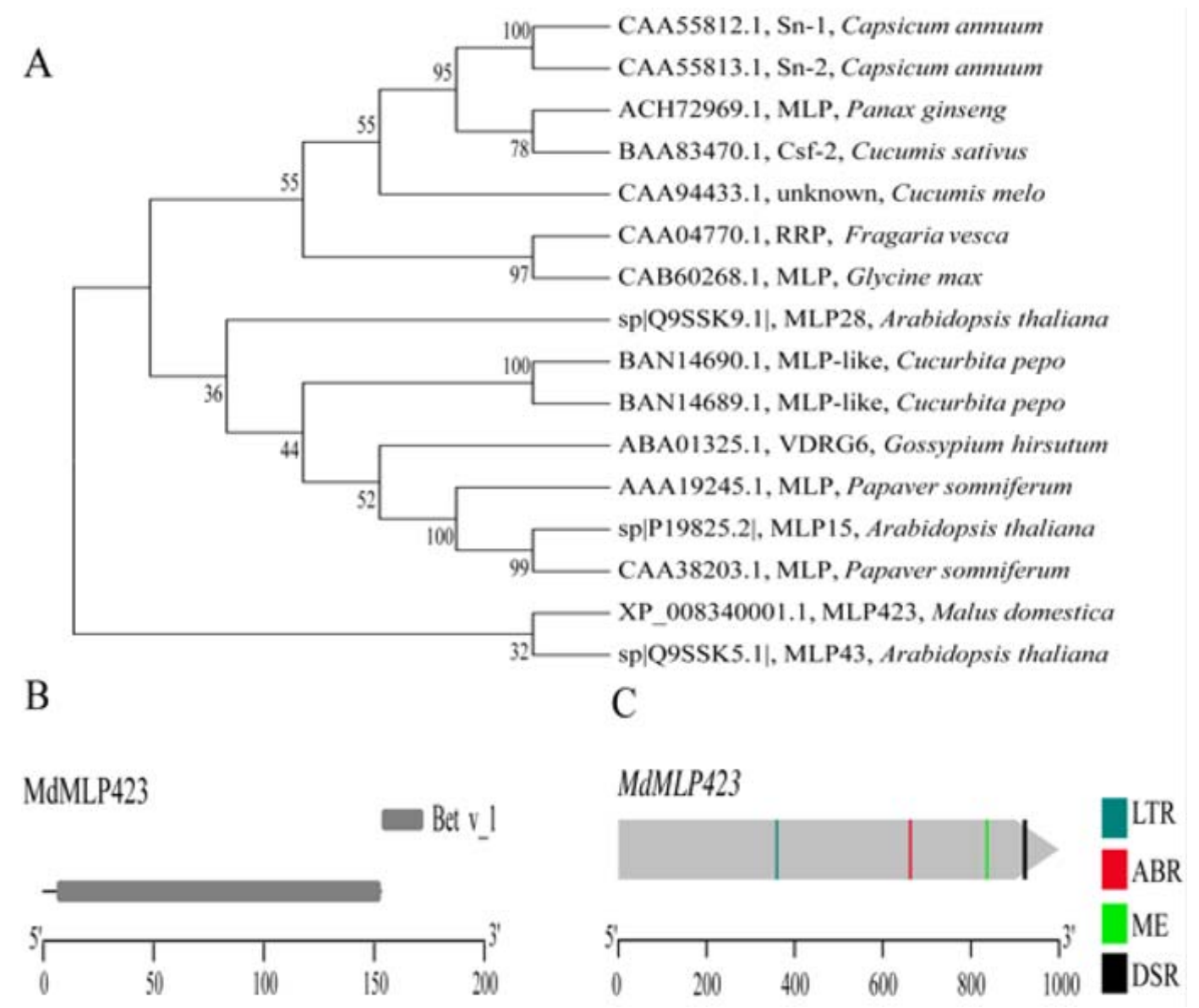

Figure 1. Phylogenetic analysis, protein structure and cis-acting elements of MdMLP423. (A) Phylogenetic analysis of the MdMLP423 protein with its orthologous genes in other plant species.

(B) Conserved domain analysis of the MdMLP423 protein. (C) Various cis-acting elements of the MdMLP423 promoter.

The phylogenetic analysis showed that the MdMLP423 protein (XP_008340001.1) was closely connected with AtMLP43 (Q9SSK5.1; Figure 1A) from A. thaliana, but shared only 35.85\% identity with AtMLP43 (Figure S1). It has been previously reported that many MLP proteins have low sequence similarity to each other but still retain a similar three-dimensional structure $[10,35]$.

We analyzed the promoter of MdMLP423 to investigate its cis-acting elements. Several stress-related cis-acting elements were identified including one low-temperature responsiveness (LTR) element and one defense and stress responsiveness (DSR) element (Figure 1C). Additionally, cis-acting elements related to hormone responses, such as the ABRE involved in ABA response, and the CAT-box related to meristem expression were also detected (Figure 1C). These results indicated that MdMLP423 might be associated with stress responses as well as plant development.

\subsection{Expression of $M d M L P 423$}

Gene expression profiles put forward useful clues to understanding a gene's role. We examined MdMLP423 transcripts from different tissues (root, stem, leaf, flower, fruit, and seedling) and under different biotic stresses (including BB and AAAP infections) using the GEO database (https://www.ncbi. nlm.nih.gov/geo/query/acc.cgi?acc=GSE42873) and qRT-PCR. The highest accumulation of MdMLP423 
was found in flowers, followed by leaves and seedings, and lower expression levels were observed in roots and stems (Figure 2A).
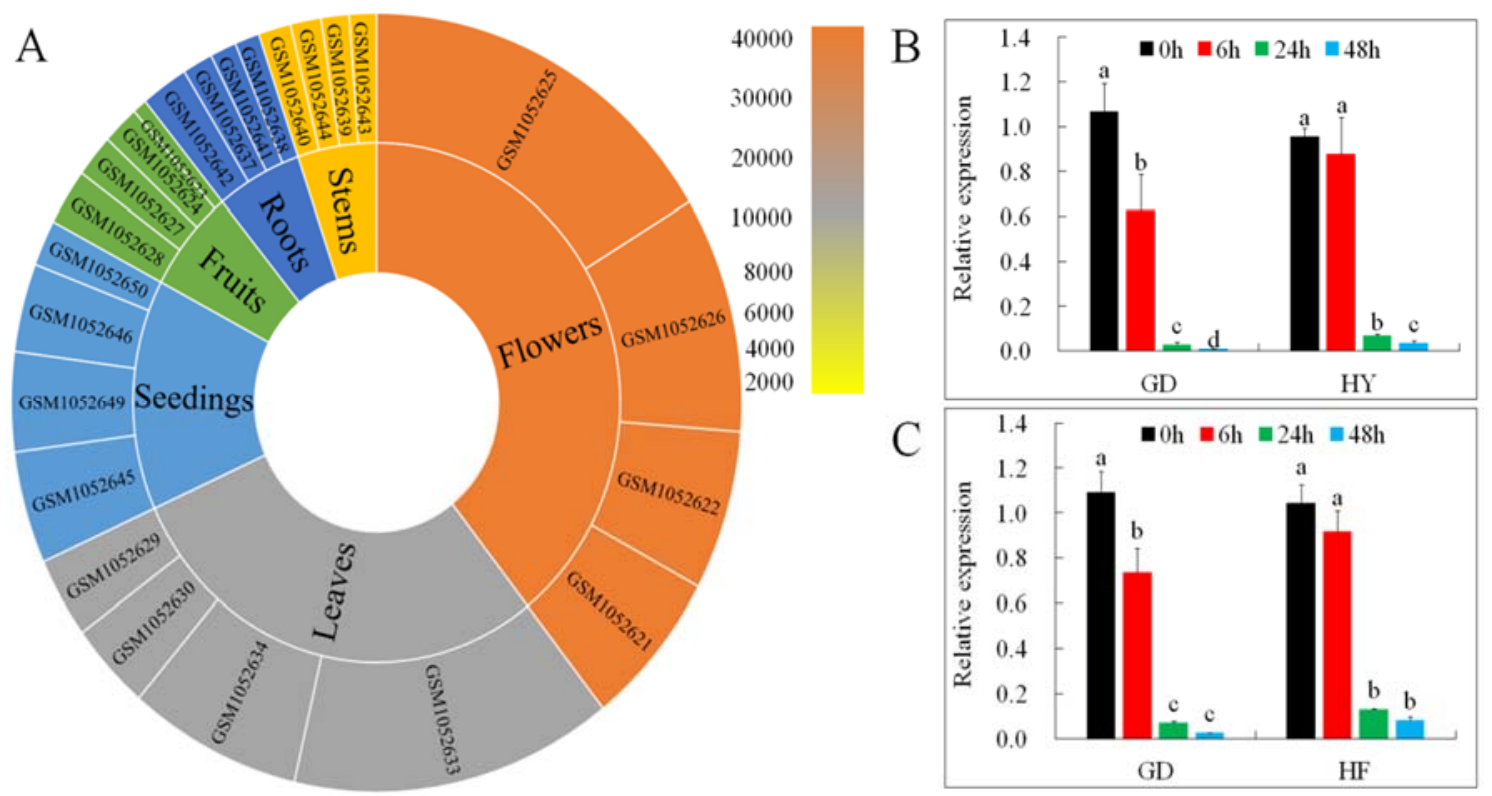

Figure 2. Expression patterns of $M d M L P 423$. (A) Expression patterns of $M d M L P 423$ in root, stem, leaf, flowers, fruit, and seedings of Malus $\times$ domestica. (B) qRT-PCR of MdMLP423 'GD' and 'HY' cultivars at $0,6,24$, and $48 \mathrm{~h}$ post-inoculation with Botryosphaeria berengeriana $\mathrm{f}$. sp. piricola (BB). (C) qRT-PCR of MdMLP423 at 0, 6, 24, and $48 \mathrm{~h}$ post-inoculation with Alternaria alternata apple pathotype (AAAP). The different lowercase letters indicate significant difference at $p<0.05$.

MdMLP423 was markedly down-regulated in response to BB infection in both the 'GD' and 'HY' cultivars, and at $48 \mathrm{~h}$ its expression was nearly 107.9-fold and 25.5-fold lower compared with non-inoculated controls, respectively (Figure 2B). AAAP infection also decreased MdMLP423 in both cultivars and by $48 \mathrm{~h}$ its relative expression was nearly 41.2 -fold and 12.6-fold lower in 'GD' and ' $\mathrm{HF}^{\prime}$, respectively (Figure 2C).

\subsection{Overexpression of $M d M L P 423$ in Apples}

Since the expression of $M d M L P 423$ was inhibited under different biotic stresses, we explored whether MdMLP423 contributed to plant stress resistance. Therefore, we transiently overexpressed $M d M L P 423$ in 'GD' leaves and assessed the expression of four known disease-resistant genes (MdRNL1, $M d R N L 2, M d R N L 4$, and MdRNL5) [32]. There was a transient but statistically significant 11.0-fold increase in MdMLP423 expression in leaves compared with the CK (Figure 3A), and all four MdRNL genes were down-regulated (1.2-1.8-fold lower; Figure 3B).

To further evaluate the role of $M d M L P 423$, we generated transgenic apple calli overexpressing MdMLP423. Three independent MdMLP423 transgenic calli lines (OE-1, OE-2, and OE-3) with high levels of MdMLP423 expression (21.8-31.8-fold higher than the control (CK) non-transgenic calli) were used for analysis (Figure 3C). The MdRNLs were down-regulated (3.5-9.5-fold) in all three transgenic lines (Figure 3D), suggesting that $M d M L P 423$ might play a negative regulatory role in biotic stresses. 


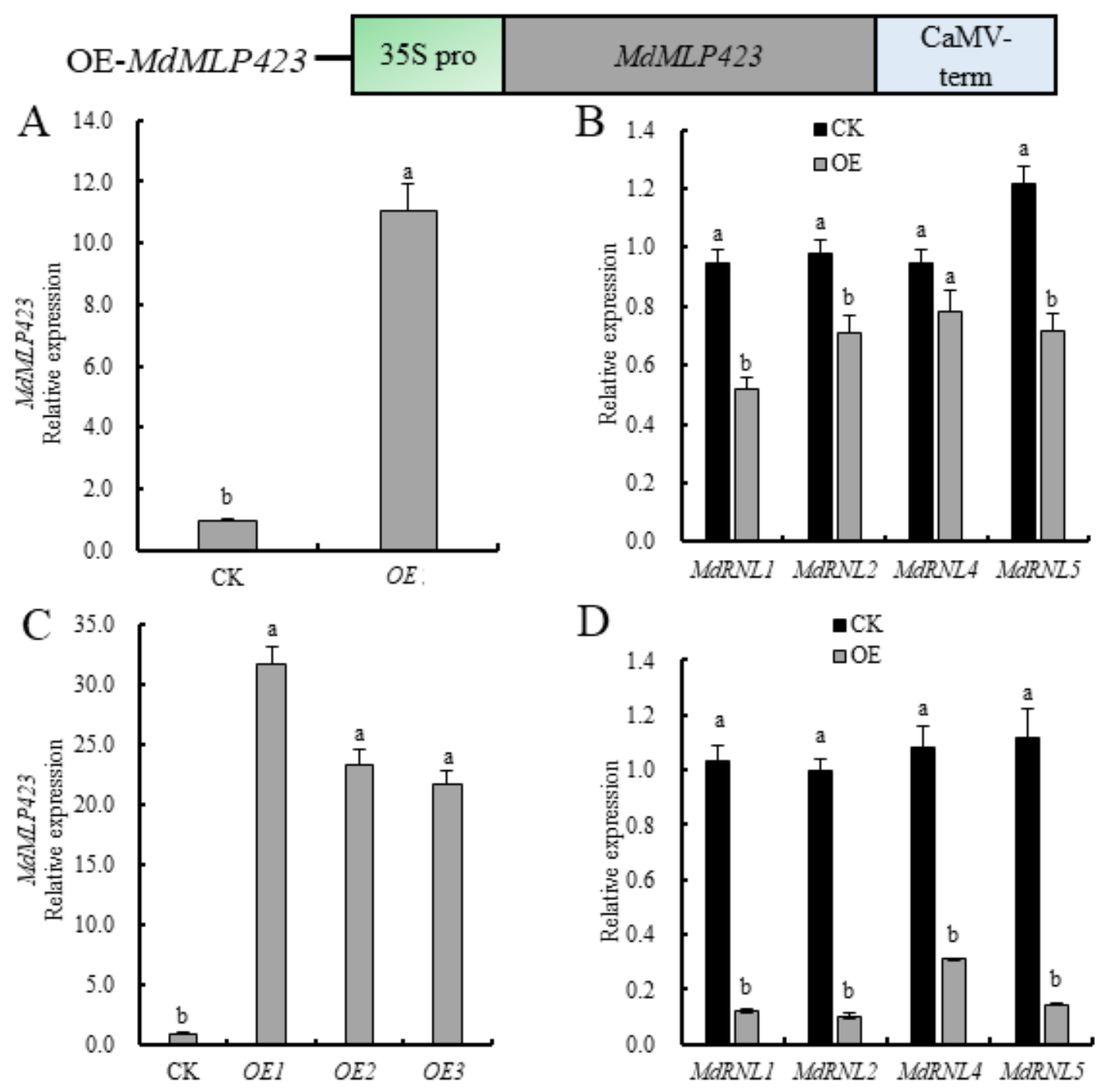

Figure 3. Overexpressing MdMLP423 in apple decreases the expression of MdRNLs. (A) Transient overexpression of MdMLP423 in 'GD' leaves. (B) Transient expression of MdRNLs in 'GD' leaves. (C) Expression of MdMLP423 in apple calli from stable genetic transformation. (D) Expression of MdRNLs in apple calli from stable genetic transformation. The different lowercase letters indicate significant difference at $p<0.05$.

Next, we compared the levels of fungal infection in the transgenic and CK calli after inoculation with AAAP or BB. A small amount of fungal mycelia was observed on the surface of transgenic calli infected by BB, but not AAAP, within $12 \mathrm{~h}$ post-inoculation (HPI). By 24 HPI mycelium were also observed on the AAAP-inoculated calli and the color around the inoculation sites became darker. At $48 \mathrm{HPI}$, the surface of the calli inoculated with BB or AAAP were almost completely covered with mycelia and the mycelia had turned yellow. The mycelium had changed color from yellow to khaki by 72 HPI. At 96 HPI the mycelium were brown and extended from the calli to the surface of culture medium (Figure 4B,D). For the CK calli inoculated with AAAP or BB, the pathogenetic time was late and the degree of the disease was mild when compared with the transgenic calli. There was no obvious change within 12 HPI, and a small amount of mycelia was observed at 24 HPI. The color around the inoculation sites became darker at $72 \mathrm{HPI}$ and at $96 \mathrm{HPI}$ almost half of the calli surface was covered with white mycelium (Figure 4A,C). 


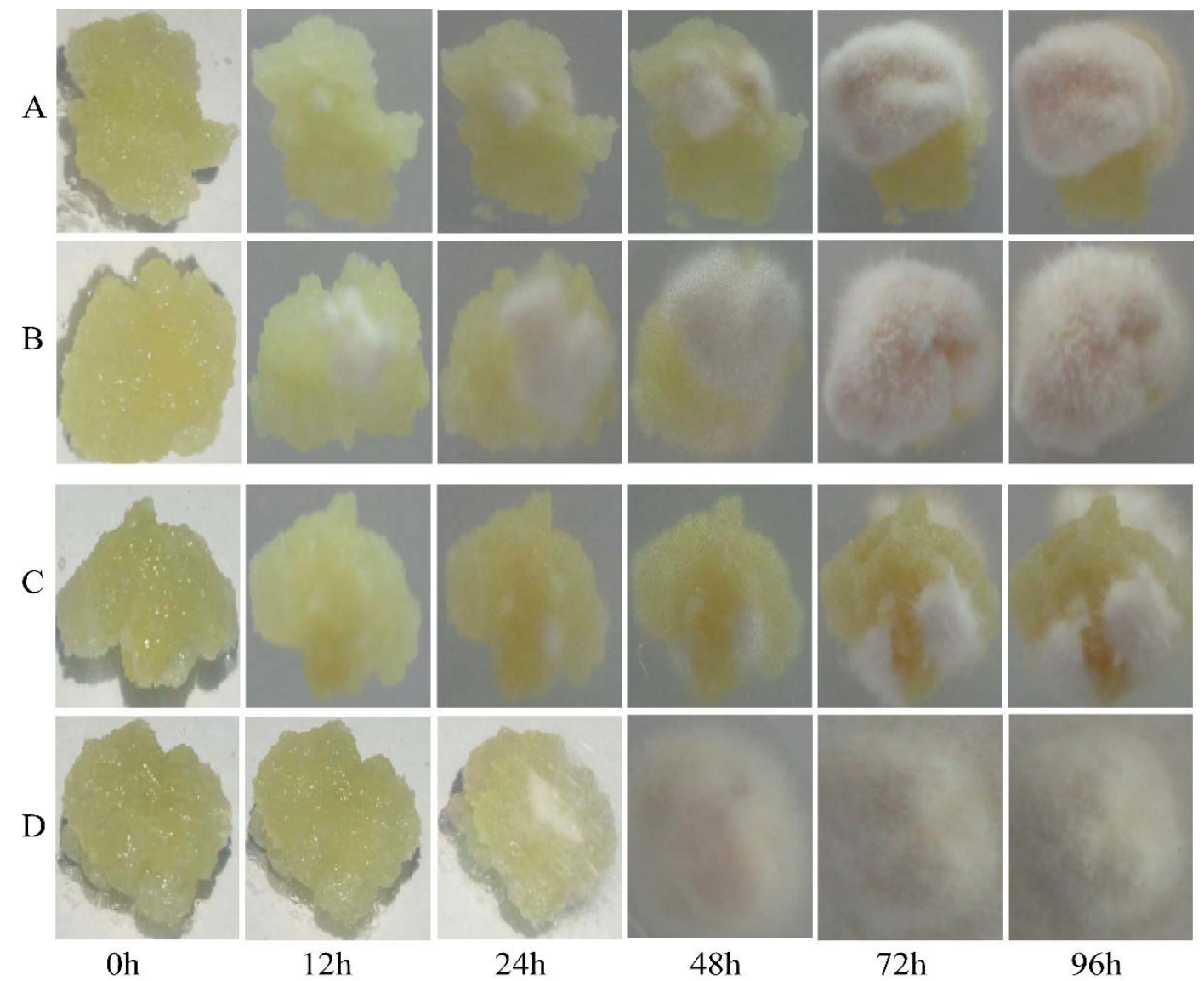

Figure 4. Infection level of calli inoculated with $\mathrm{BB}$ and AAAP. Photographs of MdMLP423-overexpressing calli (A,C) and CK calli (B,D) at 0, 12, 24, 48, 72, and $96 \mathrm{~h}$ post-inoculation with BB (A,B) or AAAP (C,D).

\subsection{RNA-Seq Data, DEG Profiles, and Functional Annotation of DEGs}

We used an RNA-seq approach to identify the genes that make the transgenic calli more susceptible to fungal infection. We extracted mRNA from 3 transgenic calli lines and 3 CK lines to construct 6 separate cDNA libraries. The results showed that the mean output data of all samples was $10.22 \mathrm{~Gb}$, and the mean match percentage of all samples to reference genomes and gene sets were $89.94 \%$ and $82.46 \%$, respectively (Table S1). In total, 40,113 genes were identified, including 36,753 known genes and 3430 predicted new genes. We screened 11,920 differentially expressed genes (DEGs) in the comparison groups (Figure 5A) and the ratio of down-regulated genes to up-regulated genes was 1.7 (Figure 5B).

GO categories were developed to assess DEG functions. All of the DEGs were classified into 44 functional categories, including biological processes (18), cellular components (15), and molecular functions (11; Figure 5C). Of the genes involved in biological processes, those regulating cellular processes were the most enriched in the transgenic calli. Genes encoding cell components were the most enriched of the cellular component genes. Genes encoding proteins with catalytic function were the most enriched of the molecular function genes. 

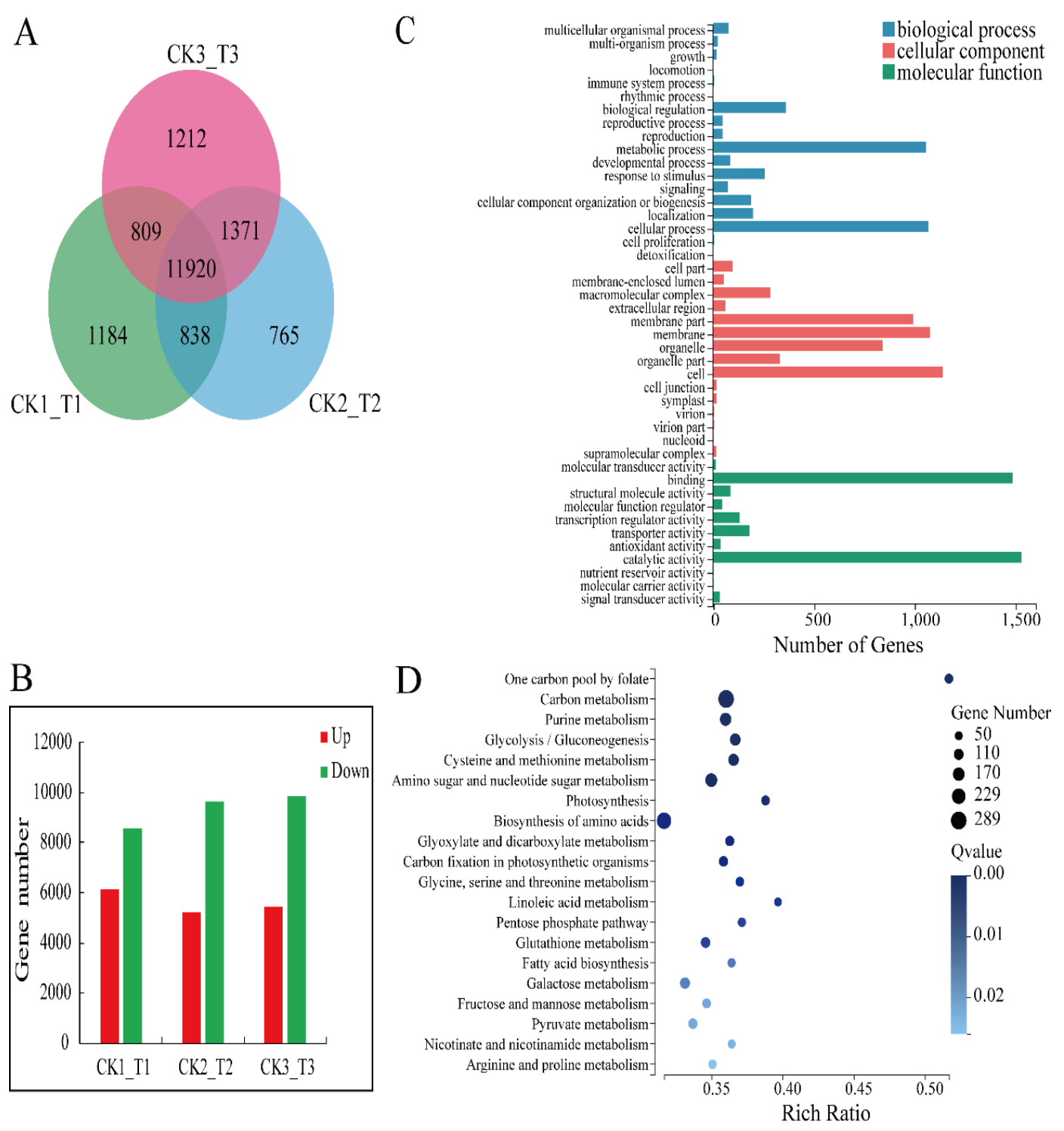

Figure 5. Analysis of differentially expressed genes (DEGs) of transgenic calli and CK. (A) Venn diagram of DEGs in comparative groups CK_1/T_1, CK_2/T_2, and CK_3/T_3. (B) The statistics of DEGs of comparative groups CK_1/T_1,CK_2/T_2, and CK_3/T_3. (C) GO categories analysis of DEGs. (D) Top 20 KEGG pathways enrichment analysis of DEGs (according to the $Q$ value).

To further evaluate the differences between the MdMLP423-overexpressing and CK calli, KEGG pathway enrichment analysis was carried out for the DEGs. The results indicated that 31 KEGG pathways were significantly enriched ( $p$ value $<0.05$; Table S2). Of these, the most enriched orthology (KO) terms were the carbon metabolism (Ko01200, 289 DEPs) and biosynthesis of amino acids (Ko01230, 254 DEGs) in the top 20 pathways (according to the Q value; Figure 5D). Above all, these results indicate that a series of different molecular changes had occurred in the transgenic calli.

\subsection{Validation by $q R T-P C R$}

We selected 12 DEGs to evaluate the RNA-Seq data. The results of the qRT-PCR of 12 DEGs were consistent with those of the RNA-Seq, which indicates that there is a high degree of repeatability between the qRT-PCR data and transcriptional abundance (Figure 6). The inconsistencies between the data sets reflect the differences between the two methods. 

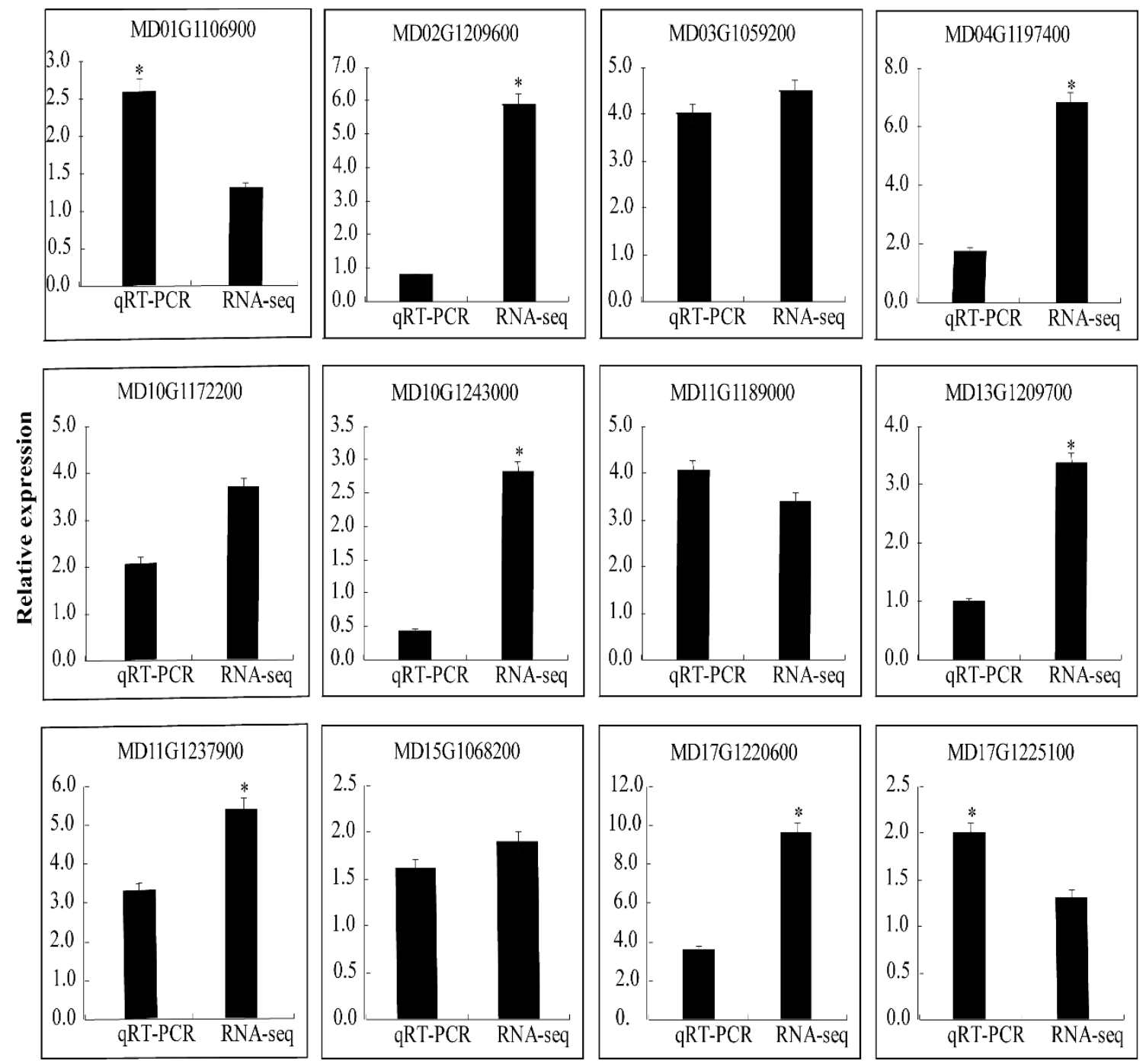

Figure 6. qRT-PCR validation of differential gene expression. The "** indicate significant difference at $p<0.05$.

\subsection{Changes in DEGs Related to Phytohormones}

In a previous study, MdMLP423 (gi|103448744) was found to improve the stress resistance of A. thaliana probably through ABA signaling [36]. Therefore, in this study, we first analyzed the changes in the expression of phytohormone-related genes. Most of the genes involved in ETH, and genes involved in SA and JA signaling was down-regulated in MdMLP423 transgenic calli (Figure 7A), and the contents of SA and JA existed similar results (Figure 7B). ABA plays important regulatory roles in plant-microbe interactions and we found that the DEGs that responded to ABA signal transduction pathways, such as MD10G1175300 and MD15G1344900, were all up-regulated (Figure 7). Additionally, the DEG (MD03G1274100) encoding BR signaling-another fundamental regulator of plant immunity-was up-regulated. 
$\mathbf{A}$

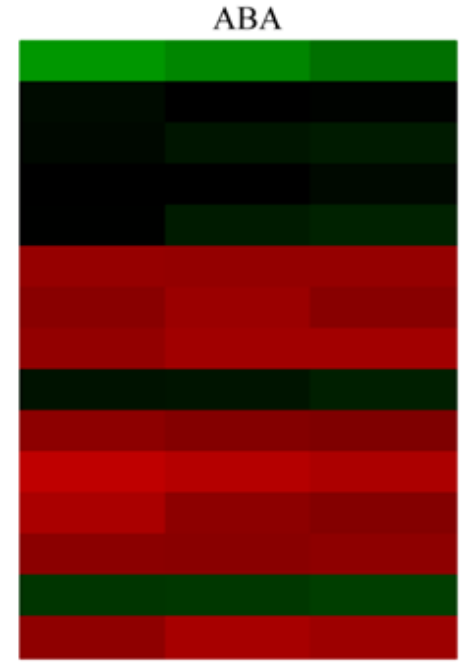

SA

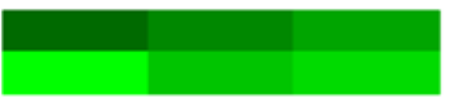
MD11G1226900

\section{MD00G1050800 MD01G1126400 MD02G1082600 MD02G1273300} MD02G1296800 MD03G1169700 MD07G1042200 MD09G1108800 MD10G1141800 MD10G1175300 MD13G1188000 MD15G1210700 MD15G1344900 MD17G1096700 MD17G1280400 MD10G1175500
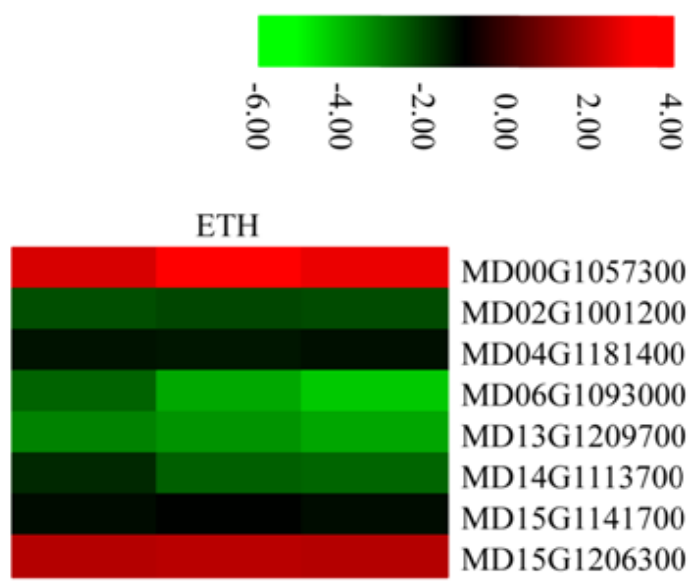

MD00G1057300 MD02G1001200 MD04G1181400 MD06G1093000 MD13G1209700 MD14G1113700 MD15G1141700 MD15G1206300

BR

JA

B

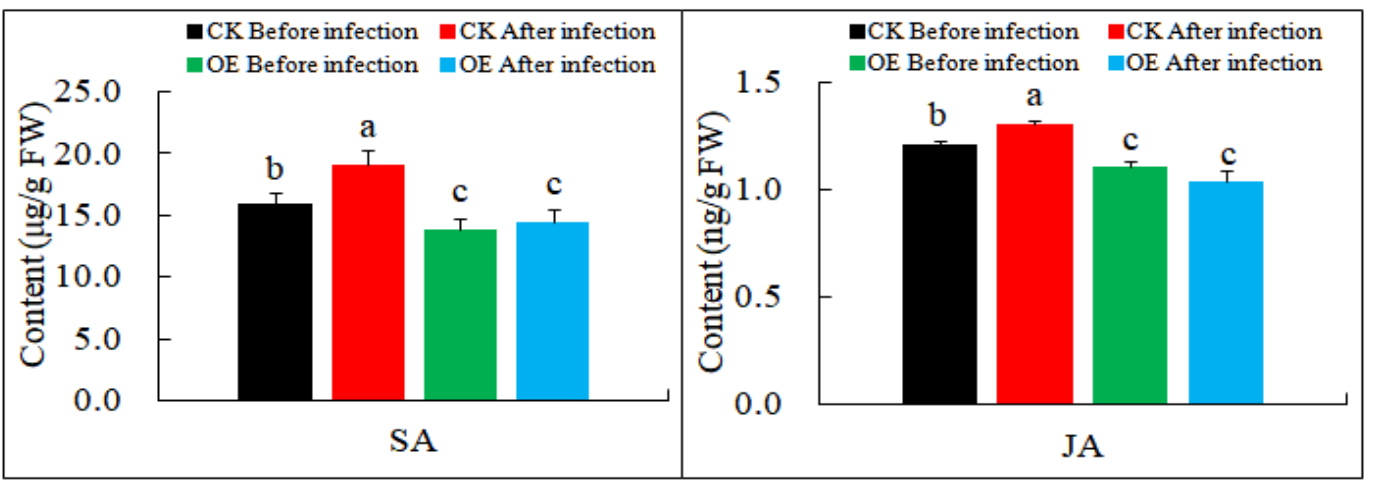

Figure 7. Expression levels of DEGs involved in phytohormone signaling pathways. (A) Heatmaps of DEGs involved in phytohormone signaling pathways, including ABA, SA, ETH, BR, and JA signaling pathways in MdMLP423-overexpressing calli. The log2|Foldchange| was colored using TBtools (red indicates the DEG was up-regulated in the $M d M L P 423$-overexpressing calli compared with the CK calli, green indicates it was down-regulated). Each row represents three independent comparisons (T_1/CK_1, T_2/CK_2, and T_3/CK_3) from left to right. (B) The content of SA and JA before and after pathogen inoculation. The different lowercase letters indicate significant difference at $p<0.05$.

\subsection{Changes in DEGs Related to Cell Wall}

In order to further explore the changes of resistance-related genes in transgenic calli, some resistance-related DEGs (Table S3) were obtained from 11,920 DEGs crossed with the PRG database (Plant Resistance Gene Database, PRGdb, http://prgdb.crg.eu/). Plant cell walls act as a physical barrier to protect cells from pathogens, and biosynthesis of cellulose (the major component of cell walls) to make primary and secondary cell walls involves different cellulose synthases. Our results revealed that the homologs of cellulose synthase A (CESA) genes in apple (MD08G1147200, MD15G1123200, and MD15G1340200) were all down-regulated and the content of cellulose reduced during AAAP and BB infections (Figure 8). This suggested that the biosynthesis of cellulose was disturbed in transgenic calli and this may contribute to the $M d M L P 423$-overexpressing lines being more susceptible to these infections. 
A
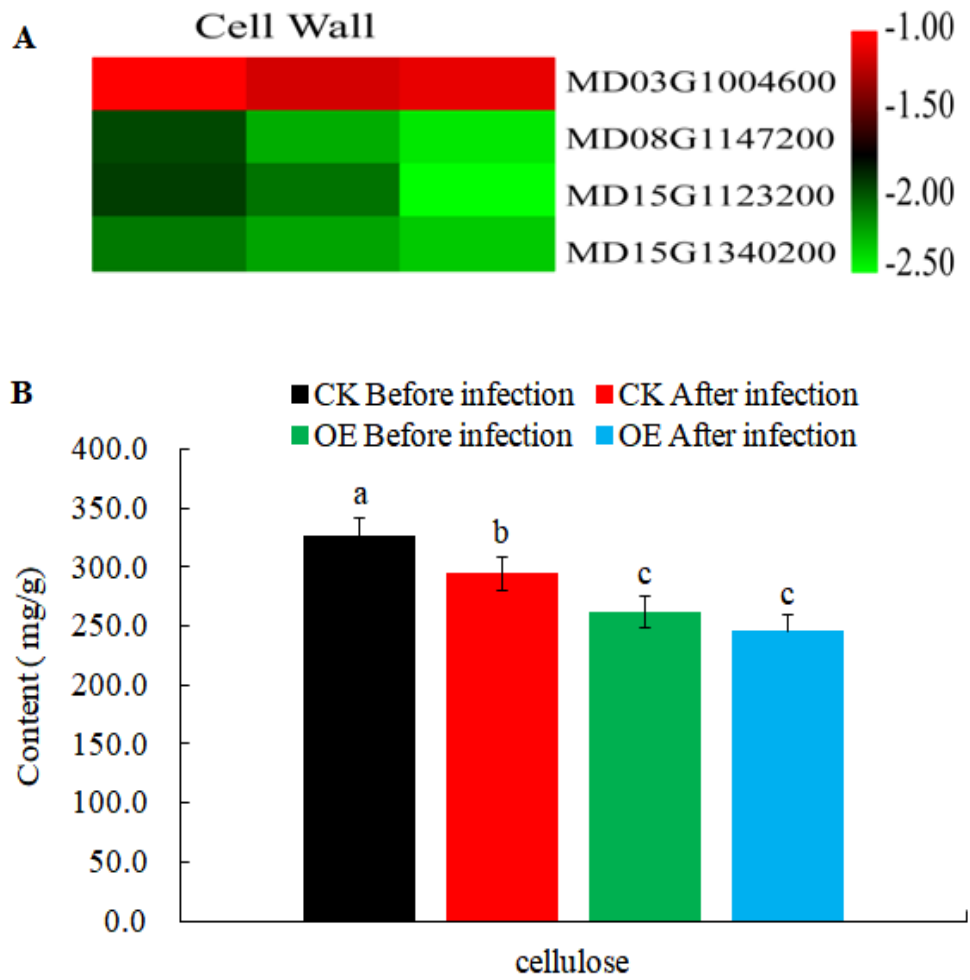

Figure 8. Expression levels of DEGs involved in cell wall reinforcement. (A). Heatmaps of DEGs involved in cell wall reinforcement. The log2|Foldchange| was colored using TBtools (red indicates the DEG was up-regulated in the MdMLP423-overexpressing calli compared with Table S1. CK_1, T_2/CK_2, and T_3/CK_3) from left to right. (B). The content of cellulose before and after pathogen inoculation. The different lowercase letters indicate significant difference at $p<0.05$.

\subsection{Changes in DEGs Related to Transcriptional Factors}

Some plant transcription factors including AP2-EREBP, WRKY, MYB, NAC, Zinc finger proteins, and $\mathrm{ABI} 3$ play important regulatory roles in defense against stress. We found that most $A P 2-E R E B P S$, $N A C s$, and some genes encoding WRKYs, MYBs, Zinc finger proteins, and ABI3s were significantly down-regulated in the calli overexpressing $M d M L P 423$ compared with the CK calli (Figure 9). For example, 32 of the 58 AP2-EREBP genes in our transcriptome data (Table S4), and 25 of the 48 NAC family-members, were significantly down-regulated in the transgenic calli. Taken together, these results indicated that overexpressing $M d M L P 423$ might change the expression of genes that encode resistance-related transcription factors, resulting in increased susceptibility to fungal infections.

\subsection{Changes in DEGs Related to Defense-Related Proteins}

Heat shock proteins (HSPs) are a subfamily of molecular chaperones that are rapidly induced under stress responses. All 13 HSP genes identified in our data belonged to the HSP70 group and 11 of these genes were down-regulated in MdMLP423-overexpressing calli compared with the CK calli (Figure 10). 


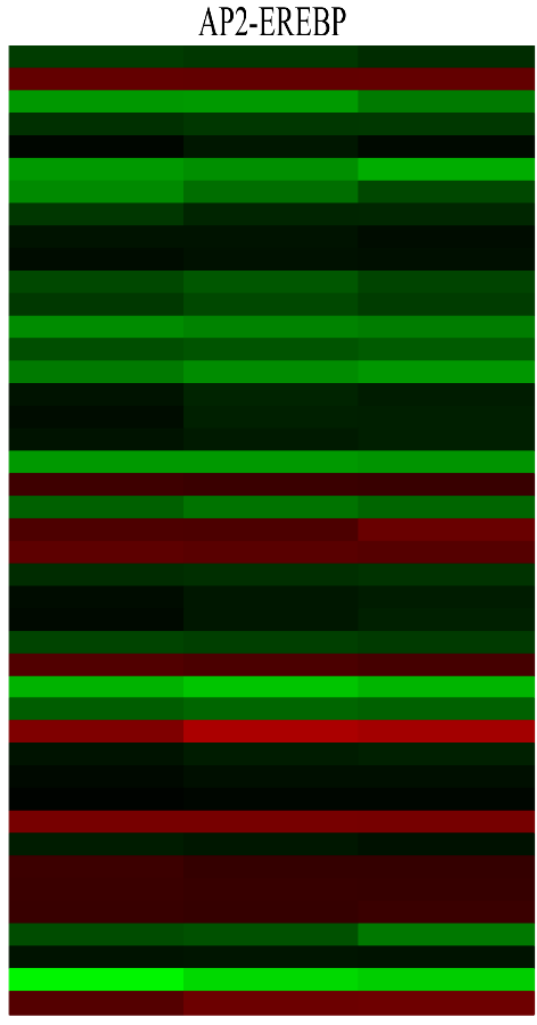

WRKY

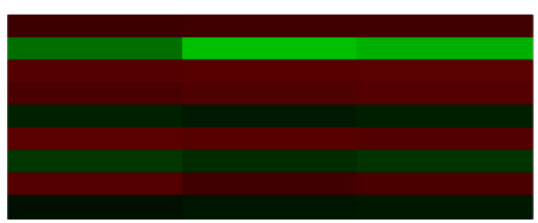

MYB

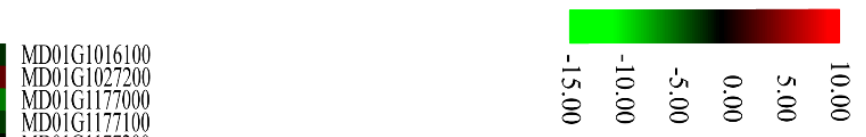

NAC

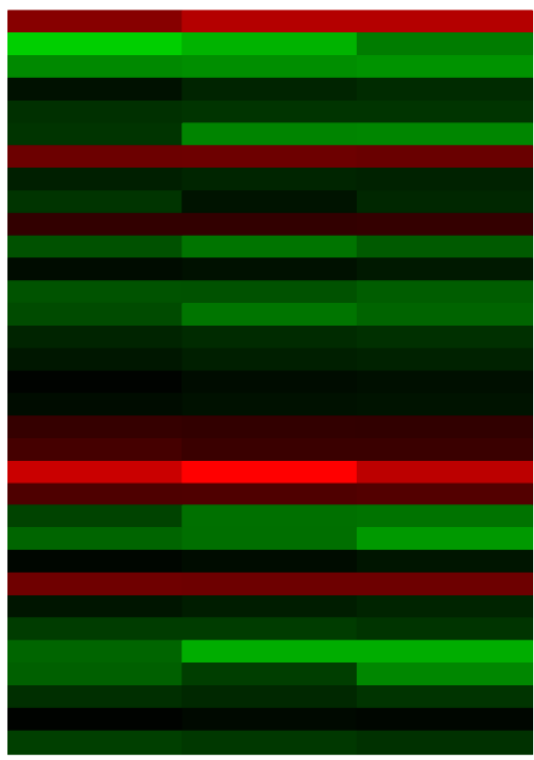

MD00G1085300 MD00G1117000 MD00G1130200 MD01G1093500 MD01G1093700 MD01G1094700 VDO1G1229900 MD03GI1 48500 MD03G1222700 MD05G1005500 VD05G1029800 MD05G1195300 MD06G1031700 MD06G1196100 MD06G1216500 MD07G1163400 MD09G1053700 MD09G1147500 MDI0G1182600 VDIOG1220600 MDI0G1238200 MD11G1167900 MD11G1239900 MDI3G1063900 MDI3G1069200 MD14G1001200 VDI4G1226900 MDI5Gi415700 MDI6G1062600 Di17G1051600 MD17G1051600

Zinc Finger Protein

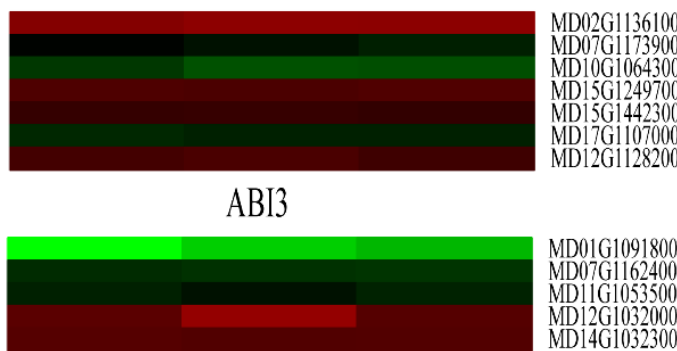

Figure 9. Heatmaps of DEGs encoding transcriptional factors. The log2|Foldchange| was colored using TBtools (red indicates the DEG was up-regulated in the $M d M L P 423$-overexpressing calli compared with the CK calli, green indicates it was down-regulated). Each row represents three independent comparisons (T_1/CK_1, T_2/CK_2, and T_3/CK_3) from left to right.

Pathogenesis-related (PR) proteins rapidly accumulate during biotic or abiotic stress. We found that PR thaumatin-like proteins were involved in defense responses regulated by $S A$, and these proteins had expression patterns that were similar to that of the SA receptor gene (MD08G1011400; Figure 7). In addition, several DEGs (MD02G1209600, MD04G1051600, MD06G1048500, and MD14G1219000) encoding defense-related chitinases were regulated by JA and showed similar expression patterns to other JA-related genes. Most $P R$ genes were down-regulated in the MdMLP423-overexpressing calli, which may explain why the transgenic calli are more susceptible to fungal infection. 


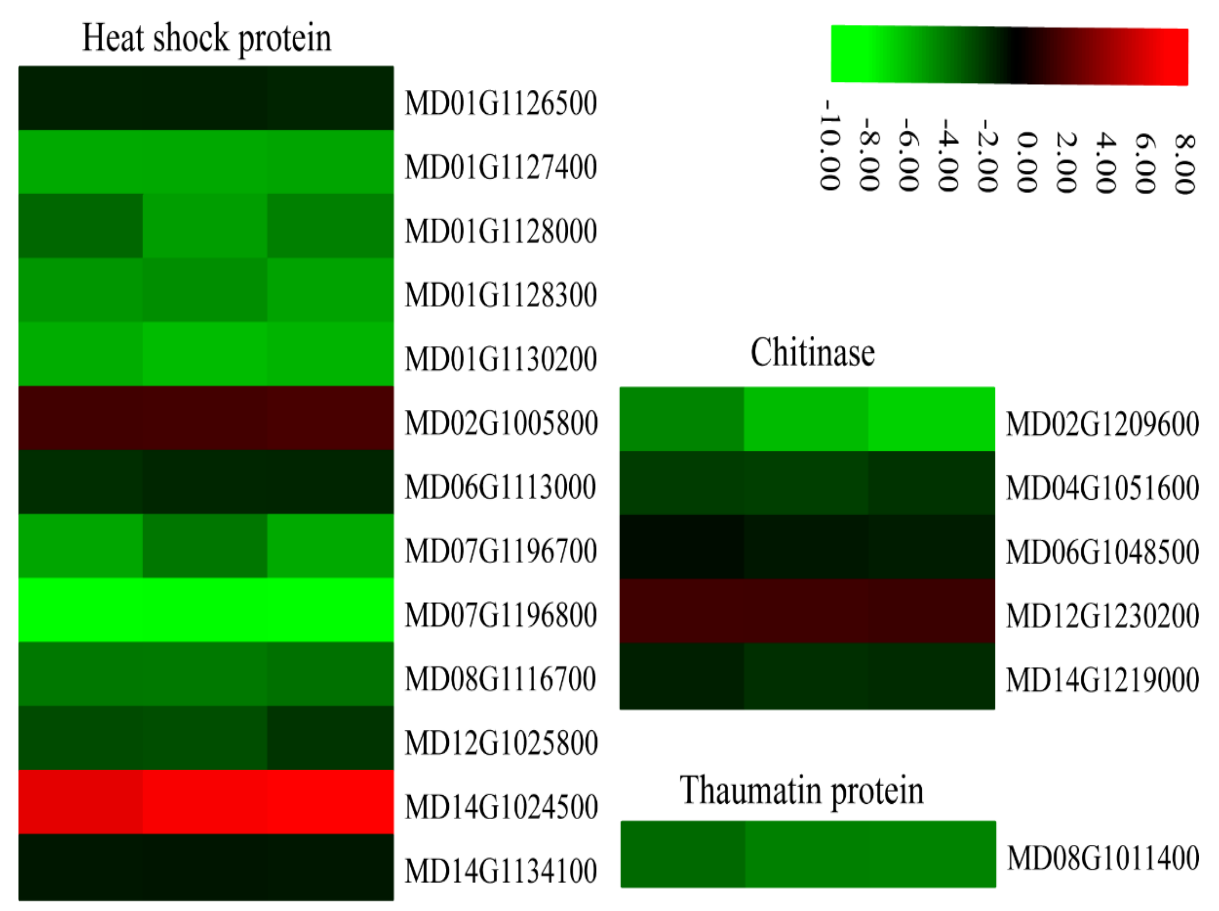

Figure 10. Heatmaps of DEGs encoding defense-related proteins. The log2|Foldchange| was colored using TBtools (red indicates the DEG was up-regulated in the MdMLP423-overexpressing calli compared with the CK calli, green indicates it was down-regulated). Each row represents three independent comparisons (T_1/CK_1, T_2/CK_2, and T_3/CK_3) from left to right.

\section{Discussion}

\subsection{The Function of MdMLP423}

The major latex proteins/ripening-related proteins (MLP/RRPs) subfamily plays important roles in defense and stress responses. In this study we identified the DSR (defense and stress responsiveness) cis-acting element of the MdMLP423 promoter, which may respond to defense- and stress-induced expression of $M d M L P 423$. Meanwhile, phylogenetic analysis revealed that MdMLP423 was closely related to AtMLP43, implying that they may have similar functions. For instance, in A. thaliana, AtMLP43 is involved in ABA signaling transduction and directly interacts with SnRK2s by combining its upstream [27]. We identified the ABA-related cis-acting element ABR in the MdMLP423 promoter, suggesting that MdMLP423 may play roles in the ABA-mediated stress tolerance pathway. Moreover, we found that the MdMLP423 protein contains a Bet $\mathrm{v} \_1$ domain, which is closely related to plant response to biotic or abiotic stress and plays crucial roles in plant growth and development, including in disease and stress resistance [10]. These results suggested that $M d M L P 423$ is a member of the Bet $\mathrm{v}_{-} 1$ protein superfamily that may be involved in biotic stress responses.

Many studies have reported that MLP proteins can respond to infection by pathogens. In A. thaliana, AtMLP3, and AtMLP28 were induced during Alternaria and Plasmodiophora brassicae infections $[37,38]$. In melon, MLP protein accumulated in phloem sap during CMV (cucumber mosaic virus) infection [39]. It also had been reported that $M L P s$ were induced by $V$. dahliae in Cotton [18,40-42]. The expression of $N b M L P 423$ in tobacco was significantly up-regulated after infection by tobacco brown spot (A. alternate) [22]. However, we found that $M d M L P 423$ was significantly down-regulated under $\mathrm{BB}$ and AAAP infections, suggesting that the roles of MLP proteins may differ between species. Meanwhile, the transient expression and stable overexpression of $M d M L P 423$ in calli down-regulated the expression of MdRNLs, and led to higher levels of BB and AAAP infection in the transgenic calli. These results suggested that MdMLP423 might negatively regulate plant responses to $\mathrm{BB}$ and AAAP infection. 


\subsection{Changes in Resistance-Related Genes}

The cell wall is an important barrier against pathogen infection in plants [20,33,43], and has been shown to increase the mechanical strength of the cell wall and resistance to pathogens [44]. Cellulose is the basic component of the cell wall and accounts for $30 \%$ of the material in the cell wall of a typical dicot. In this study we found that all the genes related to cellulose synthases were significantly down-regulated in MdMLP423-overexpressing plants and we suggest that the weakness of cell wall might be part of the reasons why the transgenic calli were more susceptible to BB and AAAP infection compared with the CK calli.

Phytohormones, such as ABA, SA, ETH, BR, and JA, play important roles in regulating the plant defense signaling network [29]. In A. thaliana, ABA has been repeatedly proved to be mainly involved in the negative regulation of plant defenses against paralysis immunity through the antagonistic SA pathway $[45,46]$. The changes in the expression of genes in ABA signal transduction pathways we observed in this study were consistent with the earlier findings. However, other studies found that ABA mainly acts as a positive regulator of immunity in soybean by stimulating callose deposition [47,48]. We found that some genes involved in ABA signaling were actually down-regulated, such as MD00G1050800, MD01G1126400, and MD02G1082600, which suggests that ABA might play different roles in plant immune responses in different species. It is generally believed that SA mediates defense responses to biotrophic and hemibiotrophic pathogens, whereas, JA and ETH are related to the defense responses to necrotrophs [49-51]. A previous study had demonstrated that genes involved in ETH and SA signaling were induced when the apple was challenged by AAAP [20]. However, we found the opposite results and infection levels were higher in MdMLP423-overexpressing calli after BB and AAAP infections. Nevertheless, the results do suggest that SA may play important roles in local immune responses against BB and AAAP. Taken together, these results revealed that activities of multiple phytohormone signaling pathways had changed in the transgenic calli and that these changes were intertwined. Thus, the susceptibility of transgenic calli to BB and AAAP infections may be caused by several different pathways.

We found that most of the genes encoding WRKY transcription factors were down-regulated in MdMLP423-overexpressing calli. Of these genes, MD03G1292900, which has high sequence similarity with PtrWRKY35, had the largest fold-change in expression (almost 128-fold) compared with the CK calli. A previous study had reported that PtrWRKY35 positively regulates JA-mediated defense signaling responses to Botrytis cinereal in transgenic $A$. thaliana plants. In our study, we found that the homolog of PtrWRKY35 in apples may play crucial roles in responses to pathogen infection. NAC genes positively regulate basic disease resistance in plants by activating $P R$ genes, or negatively regulate plant defense responses by inhibiting the expression of $P R 1$ [52-55]. One gene encoding a NAC transcription factor, MD00G1117000, was similar to AtNAC017 and was down-regulated more than 190-fold in transgenic calli compared with CK calli. At the same time a gene that encodes a thaumatin-like proteins encoding gene MD08G1011400 (PR5), was also significantly down-regulated by over 18 -fold. In $A$. thaliana, plants with mutated nac017 were more stress sensitive, suggesting that the lack of NAC transcription factors are not conducive to stress responses [56].

The expression levels of DEGs encoding defense-related proteins including HSPs and chitinases were significantly different in the transgenic calli compared to the CK calli. A previous study reported that the expression of the TaHSP70 gene in wheat was induced by Puccinia striiformis, and it was speculated that TaHSP70 may participate in the basic defenses of wheat to infection by P. striiformis through the JA signal pathway [57]. The expression of the HSP70 proteins is another important factor of apple disease resistance. Several HSP70 genes were down-regulated in the transgenic calli, suggesting that the HSP70-mediated defense signaling pathway may be damaged, resulting in increased susceptibility to fungal infections. When tobacco was inoculated with A. alternata, the content of chitinase increased significantly in disease-resistant varieties compared with susceptible varieties. This suggested that chitinase activity might promote resistance to A. alternata and other 
pathogens. Similarly, the genes encoding chitinase and $\beta$-glucosidases were down-regulated in our results, suggesting these genes may weaken the defense responses of $M d M L P 423$-overexpressing calli.

\section{Materials and Methods}

\subsection{Plant Materials and Treatment}

The leaves came from four-year-old ' $\mathrm{GD}^{\prime}$, ' $\mathrm{HF}^{\prime}$, and 'HY' plants, which were grown in the Institute of Pomology, Chinese Academy of Agricultural Sciences (Xingcheng, China (40 $37^{\prime} \mathrm{N}, 120^{\circ} 44^{\prime} \mathrm{E}$ )). The AAAP and BB came from Plant Protection Center of Institute of Pomology, Chinese Academy of Agricultural Sciences. We collected 20-day-old leaves from the three cultivars and used the suspension drop method to inoculate the leaves with the fungi [33]. For each experiment, the leaves were inoculated with liquid containing AAAP or BB in four locations on both sides of the midvein on the back of leaves. Leaves inoculated with sterile water were used as a control. Four groups of leaves were inoculated with fungus liquid or sterile water at the same time and then incubated at $25{ }^{\circ} \mathrm{C}$ under a $16 \mathrm{~h} / 8 \mathrm{~h}$ light/dark photoperiod in a sterilized glass culture dish. We collected the leaves at $0,6,24$, and $48 \mathrm{~h}$ post-inoculation (HPI) and these the four time points represented the four infectious stages.

All samples were frozen directly in liquid nitrogen and stored at $-80^{\circ} \mathrm{C}$ before RNA extraction. Each group contained three biological replicates.

\subsection{Cloning and Sequence Analysis of MdMLP423}

The coding sequence of $M d M L P 423$ was amplified from the cDNA of 'GD' using gene-specific primers (5'-ATGGCTACATTTGATG- $3^{\prime}$ and $5^{\prime}$-TTAATTAGCCAGAACATAGG-3'). DNAMAN 6.0 software was used to deduce the amino acid sequence of MdMLP423. We used Clustal W [58] to perform the MLP protein sequences alignments, and using MEGA 7.0 software [59] to construct phylogenetic trees by the NJ (neighbor-joining) method with 1000 bootstrap replicates. ExPASy (http://web.expasy.org/compute_pi) was used to predict the molecular weight (Mw) and isoelectric points (pI) of MdMLP423. SMART (http://smart.embl-heidelberg.de) was used to analyze the conserved domain of the MdMLP423 protein sequence. The upstream sequence $(1 \mathrm{~kb})$ of the transcription start site of the MdMLP423 gene was defined as promoter regions, which was extracted from 'GD' genome sequence (GDDH13) [60] by the TBtools software [61]. The cis-acting elements of promoter were analyzed by the PlantCARE database (http://bioinformatics.psb.ugent.be/webtools/plantcare/html/).

\subsection{Agrobacterium-Mediated Transient Expression Assays with pRI101-AN Constructs}

Agrobacterium-mediated expression was performed using the pRI101-AN vector driven by the $35 \mathrm{~S}$ promoter. The coding region of MdMLP423 was cloned into the pRI101-AN vector at $\mathrm{KpnI} / \mathrm{SacI}$ to generate the recombinant vector pRI101-AN:MdMLP423, using the following two primers 5'-GGTACCATGGCTACATTTGATG- ${ }^{\prime}$ and $5^{\prime}$-GAGCTCTTAATTAGCCAGAACATAGG- ${ }^{\prime}$. Then the pRI101-AN vector and the recombinant vector were transformed into the A. tumefaciens strain GV3101. The pRI101-AN construct was used in the experiment as a control, and the pRI101-AN:MdMLP423 construct was used as the test construct. According to previous protocol [33], following the addition of $50 \mu \mathrm{L}$ of $100 \mu \mathrm{M}$ acetosyringone, the vector-transformed Agrobacterium in $50 \mathrm{~mL}$ YEP was cultured at $28{ }^{\circ} \mathrm{C}$ with shaking at $180 \mathrm{rpm}$ for $5-6 \mathrm{~h}$ until $\mathrm{OD}_{600}=0.4-0.6$. The Agrobacterium was then suspended in liquid medium (10 mM MES-KOH [pH 5.2], $10 \mathrm{mM} \mathrm{MgCl}_{2}, 100 \mu \mathrm{M}$ acetosyringone) and incubated for $3 \mathrm{~h}$ before use.

For the transient expression of MdMLp423, 5 20-day-old leaves of 'GD' apple were infiltrated in the resuspended bacteria and vacuumed (10 Pa) for $30 \mathrm{~min}$ [62], then the leaves were washed 3 times with sterile water and placed in a petri dish covered with filter paper and cultured at $24{ }^{\circ} \mathrm{C}$ with a $16 \mathrm{~h} / 8 \mathrm{~h}$ light/dark photoperiod. Four days after Agrobacterium infiltration, the leaves were sampled and RNA was extracted for gene expression analysis. 
For stable expression of $M d M L P 423$, the calli of 'Orin' apple was first infiltrated in the resuspended bacteria for $15 \mathrm{~min}$ [63], and then washed 3 times with sterile water and placed in a petri dish covered with filter paper to absorb the excess water. Then the calli were transferred to the subculture medium (MS + $2.0 \mathrm{mg} \mathrm{L}^{-1}$ 2,4-D + $0.5 \mathrm{mg} \mathrm{L}^{-1} \mathrm{NAA}+2.0 \mathrm{mg} \mathrm{L}^{-1} 6-\mathrm{BA}, \mathrm{pH} 5.8$ ) for culture at $22{ }^{\circ} \mathrm{C}$ in the dark for 2 days. Next, the calli were transferred to the subculture medium containing $300 \mathrm{mg} \mathrm{L}^{-1}$ cephalosporin and $30 \mathrm{mg} \mathrm{L}^{-1}$ kanamycin for screening resistant calli. Subsequently, the resistant calli were sub-cultured several times to obtain stable resistant calli. Finally, the calli were sampled, DNA and RNA was extracted and used for PCR identification and gene expression analysis, respectively.

\subsection{Disease Resistance Identification of Transgenic Materials}

In order to identify the resistance of $M d M L P 423$-overexpressing transgenic calli, AAAP and BB were used to inoculate calli by the suspension drop method. According to a previously described methods [63], the calli of 'Orin' cultivar were used as it is the most mature genetic transformation material and is susceptible to both AAAP and BB $[63,64]$. The calli were placed in a petri dish with subculture medium and then $20 \mu \mathrm{L}$ of liquid containing the fungus was placed onto the center of the calli and then the calli were cultured at $24^{\circ} \mathrm{C}$ and a $16 \mathrm{~h} / 8 \mathrm{~h}$ light/dark photoperiod. Non-transgenic calli were used as a control. Regular images were taken to investigate the time, severity, and speed of the decay and browning the calli, and three biological replicates were performed for each treatment.

\subsection{RNA Extraction and Sequencing}

Total RNA was extracted from the six samples of MdMLP423-overexpressing transgenic and CK calli using the RNeasy Plant Mini Kit (Tiangen, Beijing, China) according to the manufacturer's protocol. For each RNA sample, RIN value $\geq 6.5$, A260/A280 ratio $\geq 1.8$, and A260/A230 ratio $\geq 1.8$. More than 200 pg high-quality RNA was amplified with oligo-dT and dNTPs (KAPA HiFi HS RM, KAPA, MA, USA), then reverse transcribed to cDNA. The average molecule length of PCR product was determined by the Agilent 2100 bioanalyzer instrument (Thermo Fisher Scientific, MA, USA). Then we used a fragment buffer ( $5 \times$ first strand buffer, Invitrogen, CA, USA) to fragment the purified cDNA from the previous step into small pieces by PCR, and the product was purified and selected by the Agencourt AMPure XP-Medium kit (Thermo Fisher Scientific, Massachusetts, USA). An Agilent Technologies 2100 bioanalyzer was used to quantify cDNA. The single strand circle DNA (ssCir DNA) was formatted as the final library. The BGISEQ-500 System (BGI-Shenzhen, China) was used for cDNA libraries sequencing. The read length of the BGISEQ-500 system was $100 \mathrm{bp}$ [65].

The clean reads were obtained by filtering the sequenced data, then the clean reads were mapped to GDDH13_v1.1 database (ftp://ftp.bioinfo.wsu.edu/species/Malus\%20\%C3\%97\%20domestica/) with Bowtie2 (http://bowtie-bio.sourceforge.net/Bowtie2/index.shtml). Then, we used the FPKM (fragments per kilobase million) method to the calculate gene expression levels. The raw sequences were deposited in the GEO website (GEO, https://www.ncbi.nlm.nih.gov/geo, accession number: GSE139972). Nr, Swiss-prot, KEGG, and GO databases were used to perform gene annotation and functional assignments. The genes with fold change $\geq 2.00$ and FDR value $\leq 0.001$ were defined differentially expressed genes (DEGs). GO enrichment and KEGG pathway enrichment were carried out to identify significantly enriched metabolic pathways and compared with the whole genome background. According to the annotation results and official classification of GO and KEGG, the DEGs were functionally classified, respectively. Generally, it was considered that the function of FDR $\leq 0.01$ was significant enrichment. For the transcription factors, we used getorf to detect the ORF of each gene, and then used HMM search to compare ORF with transcription factor protein domain, and then the ability of unigene was identified according to the characteristics of transcription factor family described by PlantTFDB (http://planttfdb.cbi.pku.edu.cn). 


\subsection{Quantitative Real Time PCR}

We used the Plant RNA Kit (Huayueyang Biotechnology Co., LTD.) to extract the total RNA. Then, a total of $1.0 \mu \mathrm{g}$ RNA was used for synthesizing cDNA according to the manufacturer's protocol (PrimeScript RT regent Kit with gDNA Eraser (TaKaRa)). Primers were designed by online Primer-Blast software (https://www.ncbi.nlm.nih.gov/tools/primerblast/index.cgi?LINK_LOC=BlastHome) and produced by Genewiz Company (China). qRT-PCR was performed on the CFX96 ${ }^{\mathrm{TM}}$ Real-Time System (Bio-Rad Laboratories) and the reaction conditions: 40 cycles of $95{ }^{\circ} \mathrm{C}$ for $5 \mathrm{~s}, 58{ }^{\circ} \mathrm{C}$ for $30 \mathrm{~s}$, and $72{ }^{\circ} \mathrm{C}$ for $30 \mathrm{~s}$. Each reaction mix contained $2.0 \mu \mathrm{L}$ previously diluted cDNA (1:5), $7.5 \mathrm{mM}$ of each primer, $12.5 \mu \mathrm{L}$ TB Green Premix DimerEraser (Perfect Real Time; TaKaRa), and 9.0 $\mu \mathrm{L}$ RNase-free water to a final volume of $25 \mu \mathrm{L}$. At least three biological replicates for each gene was performed, all of the primers were listed in Table S5. We used Actin 18S rRNA as the reference genes [65]. SPSS 18.0 software was used for significance analysis. The $2^{-\Delta \Delta C t}$ method was used to calculated the relative gene expression values [66].

\subsection{Quantification of the JA, SA Contents, and Cellulose Content}

The contents of JA and SA were measured according to the methods of You et al. [67], and the content of cellulose was measured according to the methods of Wei [68] at Cominbio Biotechnology Co., Ltd., Suzhou, China. Briefly for JA and SA, $0.1 \mathrm{~g}$ calli samples were weighed and ground in a mortar with $1 \mathrm{~mL} \mathrm{90 \%} \mathrm{methanol} \mathrm{and} \mathrm{then} \mathrm{extracted} \mathrm{overnight} \mathrm{at} 4{ }^{\circ} \mathrm{C}$. Then, the sample was centrifuged at $8000 \times g$ for $5 \mathrm{~min}$, the supernatant was taken out and the residue was leached with $0.5 \mathrm{~mL} 90 \%$ methanol for $2 \mathrm{~h}$, and combined the twice supernatant. After decompression at $40{ }^{\circ} \mathrm{C}$, the supernatant was evaporated to no organic phase (about $0.3 \mathrm{~mL}$ aqueous solution), adding $20 \mu \mathrm{L} 1 \mathrm{mg} / \mathrm{mL}$ trichloroacetic acid aqueous for shocking $1 \mathrm{~min}$. Then added $1 \mathrm{~mL}$ ethyl acetate and cyclohexane mixture $(1: 1 \mathrm{v} / \mathrm{v})$ to extract twice, transferred the upper organic phase to the new EP tube, and dried with liquid nitrogen. A volume of $0.5 \mathrm{~mL}$ methanol ( $0.1 \%$ methane acid) was used to dissolve the dried pellets. Then, the product was detected by combined high-performance liquid chromatography (HPLC) after 0.22 micron filtration. HPLC analysis was carried out for the purified product with a $10 \mu \mathrm{L}$ injection volume. The conditions were as follows: flow rate, $0.8 \mathrm{~mL} / \mathrm{min}$; column temperature, $35^{\circ} \mathrm{C}$; aliasing time, $30 \mathrm{~min}$; wavelength of the ultraviolet detector was $230 \mathrm{~nm}$ for JA, and the fluorescence detector, excitation wavelength $294 \mathrm{~nm}$, and emission wavelength $426 \mathrm{~nm}$ for SA.

For cellulose, $0.3 \mathrm{~g}$ calli samples were ground rapidly in a mortar with $1 \mathrm{~mL} 80 \%$ ethanol, then water bath at $95^{\circ} \mathrm{C}$ for $20 \mathrm{~min}$, and cooling to room temperature. The sample was centrifuged at $4000 \times g$ at $25^{\circ} \mathrm{C}$ for $10 \mathrm{~min}$, the supernatant was taken out and the residue was centrifuged again with $1.5 \mathrm{~mL} 80 \%$ ethanol and acetone, the precipitation was the coarse cell wall. Adding $1 \mathrm{~mL}$ acetic acid and soaking for $15 \mathrm{~h}$ to remove the starch, then the sample was centrifuged at $4000 \times g$ at $25^{\circ} \mathrm{C}$ for $10 \mathrm{~min}$, discarded the supernatant and dried the precipitation, and weighed the cell wall material. Then, $5 \mathrm{mg}$ cell wall material was fully ground the homogenate with distilled water, fixed the homogenate to $0.5 \mathrm{~mL}$ with distilled water and placed in an ice bath. Slowly added $0.75 \mathrm{~mL}$ concentrated sulfuric acid, mixed well and let stand for $30 \mathrm{~min}$ in the ice bath, centrifuged at $8000 \times g$ at $4{ }^{\circ} \mathrm{C}$ for $10 \mathrm{~min}$, took the supernatant and diluted it by 20 times with distilled water to be measured. Using ultraviolet spectrophotometer to detect the content and the wavelength of the ultraviolet detector was $620 \mathrm{~nm}$.

\section{Conclusions}

We found that the expression of MdMLP423 was inhibited by BB and AAAP infection. Apple tissue overexpressing MdMLP423 showed higher susceptibility to BB and AAAP than the CK and MdMLP423-overexpressing calli also exhibited weaker phytohormone signaling pathways and cell wall reinforcement. Additionally, we found that overexpressing MdMLP423 inhibited the expression of a number of pathogenesis-related transcriptional factors and genes, which resulted in the calli 
being more sensitive to fungal infection. This study provides a foundation for the research of biotic stress-related gene resources in apples.

Supplementary Materials: Supplementary materials can be found at http://www.mdpi.com/1422-0067/21/5/1879/ s1.

Author Contributions: Conceptualization, S.H., G.Y., and C.Z.; methodology, S.H., G.Y., and C.Z.; software, S.H. and G.Y.; validation, S.B., X.H. and K.L.; formal analysis, G.Y. and S.H.; data curation, S.H., and G.Y.; writing—original draft preparation, S.H. and G.Y.; writing—review and editing, C.Z.; supervision, C.Z. and P.C.; project administration, C.Z. and P.C.; funding acquisition, C.Z. and P.C.S.H. and G.Y contributed equally to this work. All authors have read and agreed to the published version of the manuscript.

Funding: This research was funded by the earmarked fund for the China Agriculture Research System (No. CARS-27); Fundamental Research Funds for Central Non-profit Scientific Institution (Y2019XK09) and the Agricultural Science and Technology Innovation Program (No. CAAS-ASTIP-2016-RIP-02); National key research and development program (2019YFD1001403).

Acknowledgments: We thank Junxiang Zhang (Plant Protection Center of Institute of Pomology, Chinese Academy of Agricultural Sciences) for providing AAAP and BB.

Conflicts of Interest: The authors declare no conflict of interest.

\section{Abbreviations}

$\begin{array}{ll}\text { MLP/RRP } & \text { Major latex protein/ripening-related proteins } \\ \text { Gly-rich-loop } & \text { Glycine-rich loop } \\ \text { BB } & \text { Botryosphaeria berengeriana } \\ \text { AAAP } & \text { Alternaria alternata apple pathotype } \\ \text { DEG } & \text { Differentially expressed gene } \\ \text { HPI } & \text { Hours post inoculation } \\ \text { SA } & \text { Salicylic acid } \\ \text { JA } & \text { Jasmonic acid } \\ \text { ABA } & \text { Abscisic acid } \\ \text { GA } & \text { Gibberellin } \\ \text { ETH } & \text { Ethylene } \\ \text { GD } & \text { Golden Delicious apple } \\ \text { HF } & \text { Hanfu apple } \\ \text { HY } & \text { Huayue apple } \\ \text { NJ } & \text { Neighbor-joining } \\ \text { Mw } & \text { Molecular weight } \\ \text { pI } & \text { Isoelectric point } \\ \text { iTRAQ } & \text { Isobaric Tags for Relative and Absolute Quantitation } \\ \text { LTR } & \text { Low-temperature responsive element } \\ \text { ME } & \text { Meristem expression } \\ \text { DSR } & \text { Cis-acting element involved in defense and stress responsiveness } \\ \text { HPLC } & \text { High-performance liquid chromatography } \\ & \end{array}$

\section{References}

1. Nessler, C.L.; Allen, R.D.; Galewsky, S. Identification and Characterization of Latex-Specific Proteins in Opium Poppy. Plant Physiol. 1985, 79, 499-504. [CrossRef]

2. Nessler, C.L.; Kurz, W.G.W.; Pelcher, L.E. Isolation and analysis of the major latex protein genes of opium poppy. Plant Mol. Biol. 1990, 15, 951-953. [CrossRef]

3. Suyama, T.; Yamada, K.; Mori, H.; Takeno, K.; Yamaki, S. Cloning cDNAs for Genes Preferentially Expressed during Fruit Growth in Cucumber. J. Am. Soc. Hortic. Sci. 1999, 124, 136-139. [CrossRef]

4. Ruperti, B.; Bonghi, C.; Ziliotto, F.; Pagni, S.; Rasori, A.; Varotto, S.; Tonutti, P.; Giovannoni, J.J; Ramina, A. Characterization of a major latex protein (MLP) gene down-regulated by ethylene during peach fruitlet abscission. Plant Sci. 2002, 163, 265-272. [CrossRef]

5. Sun, H.; Kim, M.-K.; Pulla, R.K.; Kim, Y.-J.; Yang, D.-C. Isolation and expression analysis of a novel major latex-like protein (MLP151) gene from Panax ginseng. Mol. Biol. Rep. 2009, 37, 2215-2222. [CrossRef] 
6. Lytle, B.L.; Song, J.; De La Cruz, N.B.; Peterson, F.C.; Johnson, K.A.; Bingman, C.A.; Phillips, G.N.; Volkman, B.F. Structures of twoArabidopsis thalianamajor latex proteins represent novel helix-grip folds. Proteins Struct. Funct. Bioinform. 2009, 76, 237-243. [CrossRef]

7. Inui, H.; Sawada, M.; Goto, J.; Yamazaki, K.; Kodama, N.; Tsuruta, H.; Eun, H. A major latex-like protein is a key factor in crop contamination by persistent organic pollutants. Plant Physiol. 2013, 161, 2128-2135. [CrossRef]

8. Zhu, Y.; Wu, N.; Song, W.; Yin, G.; Qin, Y.; Yan, Y.; Hu, Y. Soybean (Glycine max) expansin gene superfamily origins: Segmental and tandem duplication events followed by divergent selection among subfamilies. BMC Plant Biol. 2014, 14, 93. [CrossRef]

9. Zhang, N.; Li, R.; Shen, W.; Jiao, S.; Zhang, J.-X.; Xu, W. Genome-wide evolutionary characterization and expression analyses of major latex protein (MLP) family genes in Vitis vinifera. Mol. Genet. Genom. 2018, 293, 1061-1075. [CrossRef]

10. Radauer, C.; Lackner, P.; Breiteneder, H. The Bet v 1 fold: An ancient, versatile scaffold for binding of large, hydrophobic ligands. BMC Evol. Biol. 2008, 8, 286. [CrossRef]

11. Park, C.-J.; Kim, K.-J.; Shin, R.; Park, J.M.; Shin, Y.-C.; Paek, K.-H. Pathogenesis-related protein 10 isolated from hot pepper functions as a ribonuclease in an antiviral pathway. Plant J. 2004, 37, 186-198. [CrossRef]

12. Pühringer, H.; Moll, W.-D.; Hoffmann-Sommergruber, K.; Watillon, B.; Katinger, H.; Machado, M.L.D.C. The promoter of an apple Ypr10 gene, encoding the major allergen Mald1, is stress- and pathogen-inducible. Plant Sci. 2000, 152, 35-50. [CrossRef]

13. Lee, S.-R.; Cho, K.-O. Precambrian Crustal Evolution of the Korean Peninsula. J. Pet. Soc. Korea 2012, 21, 89-112. [CrossRef]

14. Bantignies, B.; Séguin, J.; Muzac, I.; Dédaldéchamp, F.; Gulick, P.; Ibrahim, R. Direct evidence for ribonucleolytic activity of a PR-10-like protein from white lupin roots. Plant Mol. Biol. 2000, 42, 871-881. [CrossRef]

15. Fernandes, H.; Michalska, K.; Sikorski, M.; Jaskolski, M. Structural and functional aspects of PR-10 proteins. FEBS J. 2013, 280, 1169-1199. [CrossRef]

16. Yang, C.-L.; Liang, S.; Wang, H.-Y.; Han, L.-B.; Wang, F.-X.; Cheng, H.-Q.; Wu, X.; Qu, Z.-L.; Wu, J.; Xia, G. Cotton Major Latex Protein 28 Functions as a Positive Regulator of the Ethylene Responsive Factor 6 in Defense against Verticillium dahliae. Mol. Plant 2015, 8, 399-411. [CrossRef]

17. Jones, J.D.G.; Dangl, J.L. The plant immune system. Nature 2006, 444, 323-329. [CrossRef]

18. Chen, J.Y.; Dai, X.F. Cloning and characterization of the Gossypium hirsutum major latex protein gene and functional analysis in Arabidopsis thaliana. Planta 2010, 231, 861-873. [CrossRef]

19. Li, S.L. Proteomics Analysis of Cotton and Whitefly Interaction and Functional Analysis of GhMLP423 Gene. Master's Thesis, Huazhong Agricultural University, Wuhan, China, 2016.

20. Zhu, L.; Ni, W.; Liu, S.; Cai, B.; Xing, H.; Wang, S. Transcriptomics Analysis of Apple Leaves in Response to Alternaria alternata Apple Pathotype Infection. Front. Plant Sci. 2017, 8, 22. [CrossRef]

21. Zhang, C.X.; Yuan, G.P.; Han, X.L.; Tian, Y.; Zhang, L.Y.; Cong, P.H. Application of iTRAQ-based proteomic approach for screening of resistant associated proteins in 'Huayue' apple leaves induced by Alternaria mali. Acta Phytopathol. Sin. 2018, 48, 787-798.

22. Zhang, Y. Proteomic Analysis of Tobacco Lines with Different Resistance to Brown Spot (Alternaria alternate) and Functional Study of NbMLP423. Ph.D. Thesis, Chinese Academy of Agricultural Sciences, Beijing, China, 2018.

23. Devoto, A.; Turner, J.G. Regulation of jasmonate-mediated plant responses in Arabidopsis. Ann Bot. 2003, 92, 329-337. [CrossRef] [PubMed]

24. Bari, R.; Jones, J.D.G. Role of plant hormones in plant defence responses. Plant Mol. Biol. 2009, 69, 473-488. [CrossRef] [PubMed]

25. Khan, M.I.R.; Fatma, M.; Per, T.S.; Anjum, N.A.; Khan, N.A. Salicylic acid-induced abiotic stress tolerance and underlying mechanisms in plants. Front. Plant Sci. 2015, 6, 462-469. [CrossRef] [PubMed]

26. Chan, Z. Expression profiling of ABA pathway transcripts indicates crosstalk between abiotic and biotic stress responses in Arabidopsis. Genomics 2012, 100, 110-115. [CrossRef]

27. Wang, Y.; Yang, L.; Chen, X.; Ye, T.; Zhong, B.; Liu, R.; Wu, Y.; Chan, Z. Major latex protein-like protein 43 (MLP43) functions as a positive regulator during abscisic acid responses and confers drought tolerance in Arabidopsis thaliana. J. Exp. Bot. 2015, 67, 421-434. [CrossRef] 
28. Ecker, J.R. The ethylene signal transduction pathway in plants. Science 1995, 268, 667-675. [CrossRef]

29. De Vleesschauwer, D.; Gheysen, G.; Hofte, M. Hormone defense networking in rice: Tales from a different world. Trends Plant Sci. 2013, 18, 555-565. [CrossRef]

30. Zhang, C.X.; Tian, Y.; Zhang, L.Y.; Zong, Z.R.; Cong, P.H. Comparative proteomic analysis of apple branches susceptible and resistant to ring rot disease. Eur. J. Plant Pathol. 2017, 148, 329-341.

31. Yang, Z.Y.; Kang, G.D.; Wang, Q.; Xue, G.R.; Zhang, L.Y.; Tian, Y.; Yang, L.; Zhang, C.X.; Li, W.X.; Cong, P.H. The New Yellow Apple Cultivar 'Huayue'. Acta Hortic. Sin. 2010, 37, 1877-1878.

32. Ding, A.R.; Sun, X.H.; Hou, H.M.; Sun, X.; Bai, S.H.; Zhang, Y.G.; Dai, H.Y. Cloning and Expression Analysis of MdERF113 Gene from Apple Malus x domestica Infected with Botryosphaeria dothidea. J. Qingdao Agric. Univ. (Nat. Sci.) 2018, 35, 161-170.

33. Zhang, Q.L.; Ma, C.; Zhang, Y.; Gu, Z.Y.; Li, W.; Duan, X.W.; Wang, S.N.; Hao, L.; Wang, Y.H.; Wang, S.Y.; et al. A single nucleotide polymorphism in the promoter of a hairpin RNA contributes to Alternaria leaf spot resistance in apple (Malus $\times$ domestica Borkh.). Plant Cell 2018, 30, 1924-1942. [CrossRef] [PubMed]

34. Zhang, L.; Hu, J.; Han, X.; Li, J.; Gao, Y.; Richards, C.M.; Zhang, C.; Tian, Y.; Liu, G.; Gul, H.; et al. A high-quality apple genome assembly reveals the association of a retrotransposon and red fruit colour. Nat. Commun. 2019, 10, 1494. [CrossRef] [PubMed]

35. Verma, J.K.; Kishore, D.K.; Sharma, S.K.; Sharma, A. Evaluation of Biotic and Abiotic Factors for Production of Healthy Apple (Malus $\times$ domestica) Seedling. In Mocrobial Diversity and Biotechnology in Food Security; Kharwar, R.N., Ed.; Springer: New Delhi, India, 2014; Volume 21, pp. 243-249.

36. Li, R. Investigation on Major Latex Protein423 (MdMLP423) from Apple in Response to Abiotic Stress. Master's Thesis, Shandong Agricultural University, Taian, China, 2018.

37. Schenk, P.; Kazan, K.; Wilson, I.; Anderson, J.; Richmond, T.; Somerville, S.C.; Manners, J.M. Coordinated plant defense responses in Arabidopsis revealed by microarray analysis. Proc. Natl. Acad. Sci. USA 2000, 97, 11655-11660. [CrossRef] [PubMed]

38. Siemens, D.H.; Garner, S.H.; Mitchell-Olds, T.; Callaway, R.M. Cost of defense in the context of plant competition: Brassica rapa may grow and defend. Ecology 2002, 83, 505-517. [CrossRef]

39. Malter, D.; Wolf, S. Melon phloem-sap proteome: Developmental control and response to viral infection. Protoplasma 2011, 248, 217-224. [CrossRef]

40. Qu, Z.L.; Wang, H.Y.; Xia, G.X. GhHbl: A nonsymbiotic hemoglobin gene of cotton responsive to infection by Verticillium dahliae. Biochim. Biophys. Acta 2005, 1730, 103-113. [CrossRef]

41. Wang, F.-X.; Ma, Y.-P.; Yang, C.-L.; Zhao, P.-M.; Yao, Y.; Jian, G.-L.; Luo, Y.-M.; Xia, G. Proteomic analysis of the sea-island cotton roots infected by wilt pathogen Verticillium dahliae. Proteomics 2011, 11, 4296-4309. [CrossRef]

42. Zhang, W.-W.; Jian, G.-L.; Jiang, T.-F.; Wang, S.-Z.; Qi, F.-J.; Xu, S.-C. Cotton gene expression profiles in resistant Gossypium hirsutum cv. Zhongzhimian KV1 responding to Verticillium dahliae strain V991 infection. Mol. Boil. Rep. 2012, 39, 9765-9774.

43. Thomma, B.; Cammue, B.; Thevissen, K. Plant defensins. Planta 2002, 216, 193-202. [CrossRef]

44. Jin, Z.M.; Ping, B.Z.; Shen, H.J.; Du, H.Q.; Li, R.Q.; Zhu, L.; Zhang, D.B.; Yuan, Z. Characterisation and gene mapping of a britle culm mutant bc-s1 in rice. Chin. Bull. Bot. 2016, 51, 167-174.

45. Koga, H.; Dohi, K.; Mori, M. Abscisic acid and low temperatures suppress the whole plant-specific resistance reaction of rice plants to the infection of Magnaporthe grisea. Physiol. Mol. Plant Pathol. 2004, 65, 3-9. [CrossRef]

46. Xu, J.; Audenaert, K.; Hofte, M.; De Vleesschauwer, D. Abscisic Acid Promotes Susceptibility to the Rice Leaf Blight Pathogen Xanthomonas oryzae pv oryzae by Suppressing Salicylic Acid-Mediated Defenses. PLoS ONE 2013, 8, e67413.

47. Fu, D.-Q.; Ghabrial, S.; Kachroo, A. GmRAR1 and GmSGT1 Are Required for Basal, R Gene-Mediated and Systemic Acquired Resistance in Soybean. Mol. Plant-Microbe Interactions 2009, 22, 86-95. [CrossRef] [PubMed]

48. Cao, F.Y.; Yoshioka, K.; Desveaux, D. The roles of ABA in plant-pathogen interactions. J. Plant Res. 2011, 124, 489-499. [CrossRef] [PubMed]

49. Kunkel, B.N.; Brooks, D.M. Cross talk between signaling pathways in pathogen defense. Curr. Opin. Plant Biol. 2005, 5, 325-331. [CrossRef] 
50. Glazebrook, J. Contrasting Mechanisms of Defense Against Biotrophic and Necrotrophic Pathogens. Annu. Rev. Phytopathol. 2005, 43, 205-227. [CrossRef]

51. Bruce, A.T.A.; Julián, P.P.; Manuel, M.P.P.; Marta, G.; Sánchez-Serrano, J.J.; Eric, A.S.; Roberto, S. ABA Is an Essential Signal for Plant Resistance to Pathogens Affecting JA Biosynthesis and the Activation of Defenses in Arabidopsis. Plant Cell 2007, 19, 1665-1681.

52. Jensen, M.K.; Rung, J.H.; Gregersen, P.; Gjetting, T.; Fuglsang, A.T.; Hansen, M.; Joehnk, N.; Lyngkjaer, M.F.; Collinge, D.B.; Lyngkjær, M. The HvNAC6 transcription factor: A positive regulator of penetration resistance in barley and Arabidopsis. Plant Mol. Biol. 2007, 65, 137-150. [CrossRef]

53. Kaneda, T.; Taga, Y.; Takai, R.; Lwano, M.; Matsui, H.; Takayama, S.; Isogai, A.; Che, F.S. The transcription factor OsNAC4 is a key positive regulator of plant hypersensitive cell death. EMBO J. 2009, 28, 926-936. [CrossRef]

54. Seo, P.J.; Kim, M.J.; Park, J.Y.; Kim, S.Y.; Jeon, J.; Lee, Y.H.; Kim, J.; Park, C.M. Cold activation of a plasma membrane-tethered NAC transcription factor induces a pathogen resistance response in Arabidopsis. Plant J. 2010, 61, 661-671. [CrossRef]

55. Kim, H.S.; Park, H.C.; Kim, K.E.; Jung, M.S.; Han, H.J.; Kim, S.H.; Kwon, Y.S.; Bahk, S.; An, J.; Bae, D.W.; et al. A NAC transcription factor and SNI1 cooperatively suppress basal pathogen resistance in Arabidopsis thaliana. Nucleic Acids Res. 2012, 40, 9182-9192. [CrossRef] [PubMed]

56. Ng, S.; Ivanova, A.; Duncan, O.; Law, S.R.; Van Aken, O.; De Clercq, I.; Wang, Y.; Carrie, C.; Xu, L.; Kmiec, B.; et al. A membrane-bound NAC transcription factor, ANAC017, mediates mitochondrial retrograde signaling in Arabidopsis. Plant Cell 2013, 25, 3450-3471. [CrossRef] [PubMed]

57. Qi, M.D.; Xie, X.; Wei, F.J. Research progress of HSP70s in Poaceae. Plant Physiol. J. 2019, 55, $1054-1062$.

58. Thompson, J.D.; Gibson, T.J.; Higgins, D.G. Multiple Sequence Alignment Using ClustalW and ClustalX. Curr. Protoc. Bioinform. 2002, 1, 2-3. [CrossRef] [PubMed]

59. Tamura, K.; Peterson, D.; Peterson, N.; Stecher, G.; Nei, M.; Kumar, S. MEGA5: Molecular Evolutionary Genetics Analysis Using Maximum Likelihood, Evolutionary Distance, and Maximum Parsimony Methods. Mol. Biol. Evol. 2011, 28, 2731-2739. [CrossRef] [PubMed]

60. Daccord, N.; Celton, J.-M.; Linsmith, G.; Becker, C.; Choisne, N.; Schijlen, E.; Van De Geest, H.; Bianco, L.; Micheletti, D.; Velasco, R.; et al. High-quality de novo assembly of the apple genome and methylome dynamics of early fruit development. Nat. Genet. 2017, 49, 1099-1106. [CrossRef] [PubMed]

61. Chen, C.J.; Xia, R.; Chen, H.; He, Y.H. TBtools, a Toolkit for Biologists integrating various biological data handling tools with a user-friendly interface. BioRxiv 2018, 289660. [CrossRef]

62. Chen, M.; Liu, X.W.; Shen, F.F.; Wang, P. A Highly Efficient System Establishment of Transient Expression in Lettuce. Acta Hortic. Sin. 2005, 2, 405-407.

63. Zong, Z.R.; Tian, Y.; Zhang, L.Y.; Han, X.L.; Zhang, C.X.; Cong, P.H. Cloning and Function Identification of Apple Alternaria Blotch Resistant Gene Mal d 1. Acta Hortic. Sin. 2017, 44, 343-354.

64. Lv, P.P. The Construction of Apple MdBAKIS Genes Expression Vector, Callus Transformation and Apple Ring Rot Disease Resistance Characterization. Master's Thesis, Shandong Agricultural University, Taian, China, 2016.

65. Yuan, G.; Bian, S.; Han, X.; He, S.; Liu, K.; Zhang, C.; Pei-Hua, C. An Integrated Transcriptome and Proteome Analysis Reveals New Insights into Russeting of Bagging and Non-Bagging "Golden Delicious" Apple. Int. J. Mol. Sci. 2019, 20, 4462. [CrossRef]

66. Livak, K.J.; Schmittgen, T.D. Analysis of Relative Gene Expression Data Using Real-Time Quantitative PCR and the 2- $\Delta \Delta \mathrm{CT}$ Method. Methods 2001, 25, 402-408. [CrossRef] [PubMed]

67. You, C.; Zhu, H.; Xu, B.; Huang, W.; Wang, S.; Ding, Y.; Liu, Z.; Li, G.; Chen, L.; Ding, C.; et al. Effect of Removing Superior Spikelets on Grain Filling of Inferior Spikelets in Rice. Front. Plant Sci. 2016, 7, 55. [CrossRef] [PubMed]

68. Wei, J.M. Study on Physiological and Molecular Mechanism of Fruit Texture Development and Pest-Harvest Regulation of Apple (Males Domestica Borkh). Ph.D. Thesis, Northwest A\&F University, Yangling, China, 2016.

(C) 2020 by the authors. Licensee MDPI, Basel, Switzerland. This article is an open access article distributed under the terms and conditions of the Creative Commons Attribution (CC BY) license (http://creativecommons.org/licenses/by/4.0/). 